\title{
POR UMA PERSPECTIVA IDENTITÁRIA HÍBRIDA DE ALUNO-PROFESSOR DE LÍNGUA INGLESA NO ESTÁGIO CURRICULAR SUPERVISIONADO (PRÁTICA).
}

\author{
ONE PERSPECTIVE ON HYBRID IDENTITY OF ENGLISH AS A FOREIGN LANGUAGE \\ STUDENT-TEACHER ON THE TEACHING INTERNSHIP (PRACTICUM).
}

\section{Édina Cabral Bührer}

Universidade Estadual do Centro-Oeste

\begin{abstract}
RESUMO: Trata-se de uma pesquisa stricto sensu que discute a construção da identidade de professor de língua inglesa (LI) no processo do Estágio Curricular Supervisionado (ECS). A discussão baseia-se em diferentes pesquisadores, entre eles, Stuart Hall (2005) e Homi Bhabha (1990). Para conectar o ECS e as ideias desses pesquisadores, parto do princípio de que a condição do aluno-professor (AP) de LI pode ser entendida a partir das dificuldades vivenciadas no processo de construção identitária no ECS. Neste processo parece haver ainda uma ideia "bancária" de educação (FREIRE, 1997). Para desconstruir essa ideia, é importante discutir a construção da identidade de AP por uma perspectiva de identidade híbrida $(\mathrm{IH})$ e o ECS como potencialmente produtivo para isso. Com o intuito de considerar como o AP vive as múltiplas identidades, durante o ECS, e entender a potencialidade deste espaço da formação docente para discutir a $\mathrm{IH}$, utilizei a pesquisa de base etnográfica. A partir dos dados gerados, percebi que o licenciando, durante o ECS, busca pela fixidez da identidade de professor ou de aluno de $\mathrm{LI}$ e não vive o questionamento e o conflito de estar na posição de AP de LI.
\end{abstract}

PALAVRAS-CHAVES: Língua Inglesa. ECS. Aluno-professor. Identidade híbrida.

ABSTRACT: It is a stricto sensu research that discusses the construction of English Language (EL) teacher identity in the process of Estágio Curricular Supervisonado (practicum). The discussion is based on different researchers, among them, Stuart Hall (2005) and Homi Bhabha (1998). In order to connect the practicum and the ideas of these researchers, I assume that the condition of the english language student-teacher (ST) can be understood from the difficulties experienced in the construction of her identity during the practicum. In this case, it seems there is still the "banking" concept of education (FREIRE, 1997). To deconstruct this concept, it is important to discuss the construction of the identity of ST through a particular hybrid identity perspective $(\mathrm{HI})$ and the practicum as potentially productive for this. In order to consider how the ST lives the multiple identities during the practicum and understand the potential of this teacher "training" space to discuss the $\mathrm{HI}$, I used the Ethnographic oriented research. From the data, I realized that the graduating students, during the practicum, are searching for a fixed identity of professor or student of $\mathrm{EL}$ and they do not live the questioning and conflict to be a ST of EL.

KEY WORDS: English language. Practicum. Student-teacher. Hybrid identity. 


\section{O Estágio Curricular Supervisionado}

Para compreender a pesquisa realizada, é importante inicialmente localizar o ECS dentro da problemática de discussão, sendo assim, vale mencionar que este espaçotempo da formação dos professores para a Educação Básica teve uma considerável atenção a partir da Lei das Diretrizes e Bases da Educação Nacional (LDB. 9394/96) e da criação das Diretrizes Curriculares para os Cursos de Graduação (Res. CNE/CP. 1/2002; Res. CNE 2/2002; Res. CNE/CP 9/2001; Res. CNE/CP 27/2001e Parecer CNE/CP 28/2001). A atenção a qual me refiro está no fato de que os referidos documentos alertaram para a Prática de Ensino e para o Estágio Curricular Supervisionado (ECS) destacando a importância destes na formação docente. No caso do ECS, o contido nos documentos supracitados trouxe-o para um nível de discussão não mais como uma "disciplina", mas para um entendimento de "prática social" (CURY, 1997) na intenção de colocá-lo fora de um posicionamento complementar e inseri-lo como parte integrante do processo formador e, portanto, como fundamental na formação do professor.

O sentido de ECS dado pela legislação visa romper com a ideia de oposição entre teoria e prática, buscando um significado mais abrangente à formação docente e enfatizando a relação e a relevância da transposição didática e dos conhecimentos que o aluno precisa ter e deverá ensinar nos diferentes momentos da Educação Básica (adaptado do Parecer CNE/CP 9/2001, p.23) ou, ainda, como uma forma de repensar a teoria e a prática, na qual uma não é o reflexo da outra (CNE/CP 28/2001). Esta nova possibilidade de pensar a prática e o ECS, no entanto, ainda é um desafio a ser enfrentado nos cursos de licenciatura devido ao tipo de formação que o AP recebe na Universidade, pois, segundo a conclusão do diagnóstico elaborado pela Organização de Estados Ibero-Americanos (OEI) sobre os Institutos de Formação Docente, "os professores são formados em aulas fundamentalmente teóricas, centradas em processos de memorização e com escasso tempo destinado à formação em investigação educativa" (VAILLANT, 2000, p.286).

As legislações, especialmente as citadas acima, juntamente com as pesquisas direcionadas à Formação de Professores de Língua Inglesa no contexto nacional, nos últimos dez anos, na área da Linguística Aplicada (XAVIER, 2004; GIMENEZ, 2004; 


\section{Revista do SELL \\ v. $4, \mathrm{n}^{\circ} .1$ \\ ISSN: $1983-3873$}

BARCELOS, BÁRBARA, ANDRADE, 2004; FERNANDES, 2005; RIGOLON, 2006; RODRIGUES, 2007; DANIEL, 2009, para mencionar alguns), estão aos poucos dando um novo sentido ao ECS em Língua Inglesa nos Cursos de Letras, pelo menos no que se refere à iniciativa de discutir e intervir quanto à sua importância, ou seja, como um período fundamental na formação do professor de línguas estrangeiras. Quanto à legislação, a reconfiguração pode ser observada no texto da LDB 9394/96 quando estipulou um mínimo de 300 horas para a prática de ensino e no Parecer CNE/CP 28/2001 quando conclui como "natural" o acréscimo de mais $100 \mathrm{~h}$ ao mínimo estabelecido para o Estágio Supervisionado Curricular, passando então para 400 horas, acrescentando mais 400 horas de prática, como componente curricular, totalizando de $800 \mathrm{~h}$.

(...) com as exigências legais e com o padrão de qualidade que deve existir nos cursos de licenciaturas, ao mínimo legal de 300 horas deve-se acrescer mais 100 horas que, além de ampliar o leque de possibilidades, aumente o tempo disponível para cada forma de prática escolhida no projeto pedagógico do curso. As trezentas horas são apenas o mínimo abaixo do qual não se consegue dar conta das exigências de qualidade. Assim torna-se procedente acrescentar ao tempo mínimo já estabelecido em lei (300 horas) mais um terço (1/3) desta carga, perfazendo um total de 400 horas (Parecer CNE/CP 28, 2001, p10).

O aumento de carga horária e a perspectiva dada pela legislação, em torno das modificações necessárias para uma formação mais profissional do professor da Educação Básica, envolvendo os alunos-professores, abriram caminhos para diferentes formas de pensar a formação do professor por meio do ECS. Um desses caminhos está implícito neste artigo, ou seja, uma forma de compreender a formação do AP a partir da desconstrução dos binarismos, os quais integram o processo de formação do professor da Educação Básica.

Um dos binarismos presente no curso de Letras-Inglês é a condição de AP, neste caso, diretamente relacionado à formação do professor de língua inglesa. Uma formação que tem sido vista ora pela aquisição da língua inglesa pelo licenciando na posição de aprendiz e ora pelo ensino da língua inglesa pelo licenciando na posição de professor, uma "ambiguidade de papéis" (GIMENEZ, 2004) no interior dos Cursos de Letras, a de aprendiz e a de futuro professor de uma língua estrangeira. Essas posições, entendidas neste artigo como binárias, podem ser observadas com mais amplitude quando os alunosprofessores (doravante APs) começam a vivenciar "um conhecimento do real em situação 


\section{Revista do SELL \\ v. $4, \mathrm{n}^{\circ} .1$ \\ ISSN: $1983-3873$}

de trabalho" (Parecer 28/2001, p.10), ou seja, quando efetivamente vivenciam os eventos da realidade escolar.

$\mathrm{Na}$ condição de AP de LI, o licenciando envolve-se em uma busca complexa pela identidade de professor. A complexidade está justamente no posicionamento de aluno e de professor de LI dentro de uma estrutura curricular que ainda não reconhece o ECS para além de uma "instrumentalização técnica" e da "imitação de modelos" (PIMENTA; LIMA, 2004).

A partir de um olhar de cunho etnográfico em direção à vivência de 11 APs, no interior de dois cursos de Letras (Inglês/Inglês e respectivas Literaturas), isto é, por meio de uma visão mais aprofundada das experiências vividas pelos APs durante o ECS foi possível perceber, com maior profundidade, a necessidade de discutir os posicionamentos dos APs durante o ECS. As experiências vividas, no caso desta pesquisa, foram "fotografadas" com a utilização de instrumentos de pesquisa, tais como: o questionário, a observação participante e as entrevistas (história de vida e entrevistas informais). Por meio destes geradores de informações, os APs expuseram os sentimentos (alegrias e frustrações), as dificuldades e as perspectivas da vida de APs experienciadas durante o processo do estágio. A partir das contribuições dos APs foi possível perceber os diferentes posicionamentos que o licenciando precisa assumir ou é levado a assumir durante o curso de Letras.

A estrutura curricular parece ser um dos fatores que interfere nos posicionamentos dos APs, pois coloca-os na posição de aprendiz da língua inglesa durante os primeiros anos do curso de Letras. Esta perspectiva é apontada por Gimenez (2005), quando diz que a organização curricular do curso de Letras posiciona o AP num lugar de aluno quando não lhe dá oportunidade de ocupar a posição de professor. Além disso, conforme aponta Gimenez (2005), é preciso salientar que ao chegar ao curso de Letras, o AP vem à procura do conhecimento da língua e raríssimas vezes busca a formação docente.

Embora se tenha, em algumas situações, a consciência de que o AP procura aprender o idioma ao invés de posicionar-se como professor, é preciso enfatizar que estar na condição de AP, no curso de Letras, é viver a experiência de aprender e ensinar a língua inglesa durante o processo de formação; é conviver, ao mesmo tempo, com português brasileiro e com a língua inglesa; é experienciar a cultura do outro e criar novos sentidos da própria cultura. Desta forma, esse viver, conviver e experienciar ocorridos durante o processo do estágio traz para a condição de AP um novo sentido, ou seja, uma 


\section{Revista do SELL \\ v. $4, \mathrm{n}^{\circ} .1$ \\ ISSN: $1983-3873$}

posição de aluno e de professor vivenciadas pela perspectiva de uma identidade "híbrida" (BHABHA, 1998).

\section{Identidade híbrida e educação bancária}

Na tentativa de explicar a identidade híbrida de AP faz-se necessário estabelecer uma relação entre o ESC, o AP e a concepção de identidade que se procura defender aqui. Para isso, parto do princípio de que a condição de AP durante a graduação, mais precisamente quando o licenciando vivencia a posição de professor, pode ser analisada, em um primeiro momento, pela perspectiva de "uma coisa acabada" (ser aluno é... ser professor é... ser brasileiro é... ser americano/britânico/jamaicano é...). Assim, perceber a condição AP nesta perspectiva é conceituar a identidade como fixa, pronta, acabada, enclausurada. Além disso, é entender também esse conceito por uma concepção tradicional ${ }^{1}$ de identidade.

Nesse sentido, pensar as identidades de aluno e de professor significa pensá-las a partir de lugares fixos nos quais a identidade de um e de outro passa a ser definida como uma característica imutável. Vale mencionar que, no contexto atual da educação brasileira, apesar dos movimentos contemporâneos ${ }^{2}$ em prol de uma formação docente mais crítica e reflexiva na formação inicial do professor, o licenciando ainda é visto como alguém passivo diante dos ensinamentos do professor universitário. Nesse tipo de afirmação está implícito o fato de que "fortes resquícios da metodologia jesuítica e do modelo organizacional francês ainda se encontram instalados e dominantes, muitas vezes impedindo a Universidade de cumprir seu papel de possibilitar processos de construção de conhecimento" (PIMENTA; ANASTASIOU, 2002, p. 154). Esses fortes resquícios, ainda dominantes no sistema educacional, são constitutivos da crítica de Paulo Freire à posição de depositários e depositantes de alunos e de professores que atuam na educação brasileira.

Ao colocar o AP na posição de quem recebe o conteúdo e de quem se alimenta do saber do docente universitário (tido como distribuidor do conhecimento) constrói-se uma identidade de aluno baseada na perspectiva de que o AP não tem condições de

\footnotetext{
${ }^{1}$ Por concepção tradicional de identidade entenda-se aquela conceituada por positivistas e pós-positivistas como uma característica relativamente estável que não é influenciada pela experiência de vida ou pelo processo de socialização. (TREJO GUZMÁN, 2010, p. 32).

2 Por movimentos contemporâneos, baseada em Taddei (2000), estou referindo-me à Pedagogia Crítica, Ensino Reflexivo e ao Letramento Crítico.
} 


\section{Revista do SELL \\ v. $4, \mathrm{n}^{\circ} .1$ \\ ISSN: $1983-3873$}

construir conhecimento; em decorrência disso, ele deve ser o depositário do conhecimento do outro (em nosso contexto específico, depositário do conhecimento veiculado pelo professor universitário, porque este também não é geralmente visto como construtor de conhecimento - na maioria das vezes ele é tido como um mero porta-voz do conhecimento teórico produzido fora das salas de aula da graduação).

Desta maneira, o AP forma-se na perspectiva de quem precisa ter um domínio completo do conteúdo para que possa, a seu turno, repassar para o aluno (depositário) o que aprendeu na Universidade sem que haja uma (re)construção ou apropriação significativa dos sentidos produzidos em relação aos conteúdos memorizados. Tal situação pode fazer o AP relegar à instituição de ensino, muitas vezes, a tarefa de repassar para ele todos os conhecimentos inerentes à formação de professor, sem que ele (o aluno) questione-se sobre a sua posição e a forma como o conhecimento tem sido distribuído.

As posições de depositante do professor universitário e de depositário do aluno universitário geralmente não são problematizadas durante a graduação. A ausência desse tipo de enfrentamento mostra-se mais preocupante no momento do ECS, pois o AP divide-se entre o ser aluno e aprender tudo para estar pronto ${ }^{3}$, e o ser professor sabendo pouco, não estando pronto (raramente se problematizam tais perspectivas em sala de aula, dificilmente se discute com os alunos a possibilidade de alguém estar pronto quando começou a lecionar, ou qual seria afinal o sentido de 'estar pronto').

$\mathrm{Na}$ tentativa de assumir posições fixas e imutáveis, uma ideia de oposição se instala: em uma margem, um sujeito-professor supostamente ativo, emissor, depositante; na outra margem, um sujeito-aluno passivo, receptor, depositário. Duas posições tão contraditórias em um mesmo indivíduo, se tomadas perspectivas de identidades fixas, certamente tornarão a existência do AP um processo interminável de lutas entre uma identidade e outra, ou pior, o AP acabará, provavelmente, assumindo apenas uma das identidades, a de um reprodutor das memórias arquivadas, conformando-se com o papel de repassá-las sem questioná-las, sem dar a si mesmo a possibilidade de aprender novos caminhos.

É importante aqui relacionar essas posições de aluno e de professor no contexto de ensino e aprendizagem de língua estrangeira, especificamente de língua inglesa. No

\footnotetext{
${ }^{3}$ É importante ressaltar que o sentido de 'estar pronto' deve ser lido entre aspas, pois costuma ser usado pelos APs para explicar as suas inquietações em relação à formação docente.
} 


\section{Revista do SELL \\ v. $4, n^{\circ} .1$}

ISSN: $1983-3873$

caso da LI, essas posições têm sido estabelecidas por meio do uso de métodos de ensino que acabam fixando as posições ocupadas pelo aluno e pelo professor. Cada método certamente apresenta a forma como conceitua a língua, o ensino e a aprendizagem, assim, é a partir dessas concepções que o método, no qual aluno e professor são posicionados, é embasado, ou seja,

alguns métodos são totalmente dependentes do professor como recurso de conhecimento e de direção; outros veem o papel do professor como facilitador, consultor, guia e modelo para a aprendizagem; ainda há outros que tentam colocar o papel do professor à prova, ou seja, procurando limitar a iniciativa do professor e construindo conteúdo instrucional com direcionamentos por meio de textos e de planos de aulas. O papel do professor e o papel do aluno definem o tipo de interações características da sala de aula na qual um método particular é usado. (RICHARDS; RODGERS, 2001, p. 28, tradução nossa) ${ }^{4}$.

Segundo Kumaravadivelu (1994), nenhum método de ensino de LI, focalizado na aprendizagem ou no aprendiz, pode ser realizado em sua forma "pura"; primeiro porque os métodos não são produzidos a partir da sala de aula, mas sim transpostos para ela e, por isso, muito distantes do contexto educacional. O segundo motivo, conforme estudos revelaram (como de NUNAN, 1991, apud KUMARAVADIVELU, 1994), baseia-se na perspectiva de que os produtores e elaboradores de livros didáticos não seguem fielmente a filosofia de um dado método e tampouco os professores ao entrar em contato com um tipo particular de método concordam ou seguem os princípios teóricos e os procedimentos criados para a sala de aula.

Essas questões talvez ainda não sejam suficientes para supor o posicionamento do aluno de LI como dependente do professor e, por isso, em uma posição de passividade no ensino e aprendizagem de LI. Porém, se notarmos que dentre os paradigmas educacionais presentes nas faculdades de educação,

a orientação mais poderosa é a perspectiva behaviorista que está baseada num cientificismo cartesiano-newtoniano e na psicologia behaviorista. Nesta perspectiva de educação profissional behaviorista, aprendem-se conhecimentos, habilidades e competências que são pensadas como

\footnotetext{
${ }^{4}$ Some methods are totally dependent on the teacher as a source of knowledge and direction; others see the teacher's role as catalyst, consultant, guide and model for learning; still others try to "teacher -proof" the instructional system by limiting teacher initiative and by building instructional content and direction into texts or lesson plans. Teacher and learner roles define the type of interaction characteristic of classroom in which a particular method is being used". (RICHARD; RODGERS, 2001, p. 28).
} 


\section{Revista do SELL \\ v. $4, n^{\circ} .1$ \\ ISSN: $1983-3873$}

sendo as mais relevantes pelas definições produzidas pelos especialistas do que é um bom ensino (KINCHELOE, 1993, p. 198).

Com o intuito de repensar a identidade do professor de LI em formação por uma perspectiva que possibilite a tentativa de quebrar a oposição aluno de LI/professor de LI e também não concebê-la como algo pronto, acabado, é preciso passar a percebê-la, portanto, como "híbrida" constituindo-se em um processo constante de "identificações" (HALL, 2005). Entender a condição de AP durante o curso de Letras, mais especificamente no ECS, nesta perspectiva, é tratar a identidade a partir de uma abordagem discursiva, como "(...) uma construção, como um processo nunca completado - como algo sempre 'em processo'” (HALL, 2009, p. 106). Uma construção na qual em certos momentos são acionados os diferentes sentidos em torno do conceito de professor, de aluno e da concepção de ensino e de aprendizagem de LI. Ao acionar estas diferentes concepções, o AP não deixará de ser um ou outro, mas deixará de ser plenamente um ou outro, pois a

identidade surge não tanto da plenitude da identidade que já está dentro de nós como indivíduos, mas de uma falta de inteireza que é preenchida a partir do nosso exterior, pelas formas através das quais nós imaginamos ser vistos por outros (HALL, 2005, p. 39).

A movimentação de identidades do AP poderá contribuir para que o licenciando perceba-se em constante formação. Além disso, esse processo e essa construção de identidade de professor de LI, durante o ECS, podem fazer com que a oposição aluno/professor, eu/outro, minha cultura/a cultura do outro seja vista não mais como oposição, mas a partir de uma perspectiva híbrida, conforme argumenta Bhabha, (1998, p. 22), "essa passagem intersticial entre identificações fixas abre a possibilidade de um hibridismo cultural que acolhe a diferença sem uma hierarquia suposta ou imposta". A ideia do hibridismo cultural de Bhabha possibilita que se construam novas perspectivas, incluindo a tentativa de problematizar a condição do AP.

Antes de entrar na questão do uso do conceito de "híbrido" (BHABHA, 1998) ou de como esse termo é aplicado à formação do professor de LI, é ainda necessário explicitar que, segundo Hall (2005), a identidade é algo mais complexo do que um conjunto de características partilhadas com pessoas ou grupos, como uma forma de fechamento e compartilhamento de um mesmo ideal. A identidade como "identificação", na perspectiva defendida por Hall, pressupõe que, durante o processo de formação do 


\section{Revista do SELL \\ v. $4, n^{\circ} .1$ \\ ISSN: $1983-3873$}

professor, a identidade de professor nunca estará definitivamente finalizada, podendo ser sempre alimentada ou abandonada. Essa construção e esse processo de identificação, tratando-se do AP, permitem um constante ir e vir, pois a identidade nesta perspectiva não é um conceito fixo, não se projeta vislumbrando um ponto de chegada, mas é vista como uma forma de estratégia e de posicionamento, fragmentada, múltipla e em constante mudança.

Ressalto que, a despeito da utilização do sentido discursivo de "identificação", o termo identidade também é utilizado no decorrer desta discussão, pois a finalidade aqui não é usar um termo como substituição de outro, como se um fosse mais verdadeiro do que o outro, mas utilizá-lo "sob rasura" (DERRIDA, 2008; HALL, 2009). Não tenho o objetivo de acorrentar o termo a uma ideia anterior por meio da qual foi significado, mas acreditar na possibilidade de construir novos sentidos por meio dele. Vale ressaltar, no entanto, que é necessário pensar na ideia anterior ${ }^{5}$ e primeira de identidade para então entender o sentido de identificação e também de identidade híbrida, pois é por intermédio da ideia primeira e também dos rastros que têm constituído o entendimento do conceito de identidade que novas possibilidades de pensá-la podem ser construídas.

Durante o processo de ECS, na construção da identidade de professor de LI, o licenciando do curso de Letras pode deparar-se com situações contraditórias envolvendo as identidades que o constitui, as quais podem conduzi-lo à busca pela estabilidade ante uma posição e outra, como aluno e professor, como falante do português brasileiro e falante do inglês - como alguém desejoso de dominar a língua do "Outro estrangeiro" 6 (KIERNAN, 2010, p. 5) - e com as várias identidades vividas ou sonhadas antes e durante o curso de Letras, tais como: pedagogo, turismólogo, músico ${ }^{7}$, entre outras.

Essas situações contraditórias, ao invés de serem pensadas e vividas como opostas, incoerentes e fixas, podem ser percebidas como híbridas, coerentes e múltiplas. Essa mudança na forma de interpretar a identidade do AP abre uma possibilidade de negociação ${ }^{8}$ entre a situação de aprendente e a de ensinante de $\mathrm{LI}$, de falante do português brasileiro e falante de inglês, de nós e eles. Mais do que um choque de

\footnotetext{
${ }^{5}$ Por anterior e primeira entenda-se o conceito de identidade fixa.

${ }^{6}$ O Outro Estrangeiro refere-se ao falante nativo de inglês.

7 Estas são "identidades" vividas, almejadas ou sonhadas pelos alunos-professores que participaram da pesquisa antes ou durante o curso de Letras, conforme informado por eles.

${ }^{8}$ Ao apropriar-me do termo negociação de Homi Bhabha, eu busco um sentido que sugere o entendimento das identidades que envolvem o AP de LI como uma interconexão contínua de troca e que produzem um reconhecimento recíproco e inconstante das diferenças entre elas.
} 


\section{Revista do SELL}

v. $4, n^{\circ} .1$

ISSN: $1983-3873$

identidades, o espaço ocupado pelo AP, tal qual a perspectiva dos embates culturais de Homi Bhabha, traduz-se como uma fronteira que "se torna o lugar a partir do qual algo começa a se fazer presente" (BHABHA, 1998, p. 24).

Estar na posição de AP assemelha-se ao viver na fronteira que, ao contrário de um lugar de demarcação, aproxima-se da metáfora de uma ponte "que reúne enquanto passagem que atravessa" (BHABHA, 1998, p. 24), pois o AP ao experienciar a posição de professor de LI, responsável por uma sala de aula durante o processo de ECS, não deixa de ser aluno, assim como não deixa de ser falante do português brasileiro para ser falante de inglês. A posição de AP, por uma perspectiva de identidade híbrida ou de viver na fronteira, remete-nos a teoria pós-colonial ou póscolonial e as consequências advindas das várias possibilidades de sentidos que se pode atribuir a ela.

\section{A ideia póscolonial e a relação com a condição de aluno-professor de LI}

Para discutir os conceitos mencionados a partir da perspectiva da $\mathrm{IH}$ e, portanto, a partir de uma perspectiva póscolonial ${ }^{9}$, torna-se imprescindível contextualizar teoricamente o viés a partir do qual se olham tais conceitos; em outras palavras, é fundamental conhecer o caminho teórico já percorrido por Bhabha para que se possa entender os motivos que me levaram a criar um sentido muito particular e único de leitura da teoria, advinda de um contexto pós-colonial, para a formação inicial do professor de língua inglesa.

Primeiramente, é preciso esclarecer que a discussão sobre a identidade de AP de LI toma como base a teoria de Homi Bhabha (1998; 1990), da qual busquei ressignificar os conceitos de "terceiro espaço" e de "hibridismo" e contextualizá-los na vivência prática do AP durante o estágio em LI. Desta forma, a teoria não é utilizada em sua totalidade, haja vista que há outras questões abordadas por Bhabha na teoria pós-colonial que não serão discutidas aqui, trata-se de um recorte para um contexto novo, no qual os conceitos utilizados representam uma tentativa de aprender mais sobre a teoria enquanto a utilizo.

Na sequência, é necessário fazer algumas considerações sobre o prefixo "pós", pois, conforme aponta Hall (2011, p. 54), o fenômeno pós-colonial "poderia nos fazer desviar por um labirinto conceitual do qual poucos viajantes retornam. Contentemo-nos,

\footnotetext{
${ }^{9}$ O uso do póscolonial sem hífen é proposital. No decorrer do texto esse uso é exemplificado.
} 


\section{Revista do SELL \\ v. $4, \mathrm{n}^{\circ} .1$ \\ ISSN: $1983-3873$}

por enquanto, em afirmar que o pós-colonial não sinaliza uma simples sucessão cronológica do tipo antes/depois".

A partir do conselho do autor é preciso ir um pouco mais além e compreender que o prefixo "pós" não indica apenas a ideia de um acontecimento posterior, mas incita o leitor a compreender as implicações que subjazem ao seu uso. Para Bhabha (1998, p. 19), o controvertido prefixo marca a existência contemporânea como "uma tenebrosa sensação de viver nas fronteiras do "presente"”. Segundo o autor, "pós" representa uma ideia de além, o qual está entre aspas, ou seja, é um "além" que não é nem um novo começo nem uma renúncia aos acontecimentos passados, mas um momento de transição. Nessa transitoriedade, o presente e o passado cruzam-se constantemente, o lá e o cá se atravessam produzindo formas complexas de diferença e identidade. Assim, não significa um simples antes e depois, mas um espaço-tempo que permite perceber novos posicionamentos que surgem num momento contingente. Apesar do ponto de vista de Bhabha, definir ou chegar a um consenso a respeito do referido termo é uma tarefa difícil, pois a teoria pós-colonial e o pós-colonialismo são termos contestados assim como o são as associações e origens relativas a eles (ANDREOTTI, 2011).

De acordo com Gandhi (1996), os desacordos oriundos da forma como a teoria é utilizada e a ausência de uma metodologia coerente (devido à nebulosidade que permanece em relação ao termo) refletem nas discussões que frequentemente tentam definir a terminologia pós-colonial. Sendo assim, alguns críticos utilizam o termo hifenizado como uma forma de tempo que marca o processo de descolonização, enquanto outros pesquisadores questionam profundamente a implicação da separação cronológica entre o colonialismo e os seus resultados (GANDHI, 1996). Para a autora, esse questionamento toma como base o fato de que a condição pós-colonial parece implicar o início de algo, mais do que o final da ocupação colonial. Nessa perspectiva, o uso do termo sem o hífen é mais sensível à extensa história das consequências da colonização. É nesse sentido que o uso do termo póscolonial, sem hífen, é utilizado aqui, ou seja, para enfatizar que as consequências da colonização ainda se fazem presente, até mesmo na formação docente. Certamente que as características dessa neocolonização são diferentes e mais globalizadas.

Vale considerar também que a discussão que se segue, por meio de uma perspectiva do pós-estruturalismo, busca por um lugar de enunciação que permita um desvio dos conceitos essencialistas e a infração das fronteiras culturais impostas pelo 


\section{Revista do SELL}

V. $4, n^{\circ} .1$

ISSN: $1983-3873$

poder colonial. Desta forma, procuro imaginar a possibilidade de relações que não estejam ligadas por meio da repressão, da dominação ou da oposição que promovem alguns e menosprezam outros. Por isso, ao utilizar uma perspectiva póscolonial (sem hífen) nesta proposta de discussão, procuro também fazê-la por meio do pósestruturalismo.

O caminho, portanto, se faz pela tentativa de desconstrução dos inúmeros binarismos de que é feito o conhecimento que configura o universo educacional, no qual as relações, científico/não científico, masculino/feminino, branco/negro, sexual/homossexual (aluno/professor; teoria/prática) são questionadas, além de se interrogar também a "concepção de sujeito-autônomo, racional, centrado" (SILVA, 2010, p. 124). Adotar uma perspectiva póscolonial pelo viés pós-estruturalista é pensá-la por meio da desconstrução dos binarismos, ou seja, "mostrar como aparentemente simples posições binárias como a presença versus ausência, ou discurso versus escrita - são de fato extremamente complexos (...)" (HUDDART, 2006, p. 11, tradução nossa).

Bhabha debate a condição daqueles que vivem as binaridades a partir das fronteiras culturais cujo interesse "está voltado para os espaços de enunciação que não sejam definidos pela polaridade dentro/fora, mas se situem entre as divisões, no entremeio das fronteiras que definem qualquer identidade coletiva" (COSTA, 2006, p. 122).

Interessado no contexto dos deslocamentos, relacionado à experiência pós-colonial das migrações, diásporas e da escravidão, Bhabha controverte o lugar da cultura criticando a concepção estável e monolítica deste conceito, atribuindo-Ihe um novo sentido, conforme escreve Menezes de Souza:

para Bhabha, no projeto pós-colonial, em oposição ao conceito dominante de cultura como algo estático, substantivo e essencialista, a cultura passa a ser vista como algo híbrido, produtivo, dinâmico, aberto, em constante transformação; não mais um substantivo, mas um verbo, "uma estratégia de sobrevivência" (2004, p. 125).

A ideia de uma cultura híbrida possibilita pensar também em identidades híbridas a partir da relação fronteiriça entre as culturas. Salientando, porém, que pensar em identidades híbridas não significa, conforme adverte Hall (2011, p. 71), uma forma de contrapor indivíduos híbridos com outros tradicionais ou modernos, mas "trata-se de um processo de tradução cultural, agonístico, uma vez que nunca se completa, mas que permanece em sua indecidibilidade". Esse processo de tradução, segundo Bhabha, 


\section{Revista do SELL}

v. $4, n^{\circ} .1$

ISSN: $1983-3873$

não é simplesmente apropriação ou adaptação; é um processo através do qual se demanda das culturas uma revisão de seus próprios sistemas de referência, normas e valores, pelo distanciamento de suas regras habituais ou "inerentes" de transformação. Ambivalência e antagonismo acompanham cada ato de tradução cultural, pois o negociar com a "diferença do outro" revela uma insuficiência radical de nossos próprios sistemas de significado e significação. (BHABHA, 1997, apud HALL, 2011, p. 71, grifos do autor).

Certamente que a condição híbrida do AP não se dá comparativamente àqueles que cruzam as fronteiras que dividem os países, mas assemelha-se ao processo de hibridação cultural pelo contato e construção do sujeito por meio das diversas culturas pelas quais ele foi e é formado; além do contato do português brasileiro com a LI por meio da influência que essa língua, cada vez mais, exerce nos APs e nas pessoas conectadas por meio das relações motivadas pela globalização. $O$ processo de hibridação está relacionado também à revisão de sistemas de referência do que é ser falante do português brasileiro e do que é ser falante de outras línguas como o inglês por exemplo, pois o AP é envolvido pelas diferentes culturas que o define, pois "nenhuma cultura é completa em si mesma, nenhuma cultura se encontra a rigor em plenitude" (BHABHA, 1990, p. 210/tradução nossa).

Para compreender a incompletude da cultura, com a finalidade de explicar o híbrido, é importante trazer o conceito de tradução de Bhabha, pois é a partir dele, que o híbrido pode ser percebido. Para Bhabha o original é passível de tradução, "mas não no sentido linguístico do termo, como a tradução de um livro escrito em português para o inglês" (BHABHA; COMAROFF, 1990, p. 210), e sim como uma cópia, uma transferência, uma simulação, pois "o 'original' nunca está acabado ou completo em si. O 'originário' está sempre aberto à tradução [...] nunca tem um momento anterior totalizado de ser ou de significação - uma essência" (BHABHA, 1990, p. 210), é nesse sentido que a cultura não é completa em si mesma, pois é construída a partir do Outro. Conforme argumenta Bhabha, "a razão pela qual um texto ou sistema de significados culturais não pode ser autossuficiente é que 0 ato de enunciação cultural -o lugar do enunciado- é atravessado pela différance da escrita" (1998, p. 65, grifos do autor). Se nenhuma cultura é completa em si mesma e somos de certa forma traduzidos de um Outro e este Outro de outro e assim sucessivamente, o AP, como qualquer pessoa, tem uma identidade híbrida.

Uma das consequências advindas do posicionamento em relação à língua e ao espaço de falante do português brasileiro, quando o AP propõe-se a aprender a língua e também a ensiná-la, é a intensificação do encontro com o Outro Estrangeiro, numa 


\section{Revista do SELL \\ v. $4, n^{\circ} .1$ \\ ISSN: $1983-3873$}

espécie de convite ao AP para uma tomada de posição, por meio da revisão do significado do que é ser falante do português brasileiro e do que é ser falante do inglês na condição de AP. Quando essa tomada de posição não acontece por si só, deveria ser provocada no decorrer do curso de Letras, uma vez que os APs ainda têm sido conduzidos por uma visão de ensino hierarquizada não apenas do conhecimento, mas também das subjetividades, sendo muitas vezes posicionados como aprendizes sem um questionamento sobre a função do inglês no contexto brasileiro. Ao provocar esse novo posicionamento tem-se o objetivo de possibilitar que os APs questionem sobre o ensino da LI, principalmente a forma como ele tem sido conduzido nas escolas, o propósito de ensinar a LI, as implicações de se usar, ou não, a língua materna em sala de aula, a posição do professor de LI no contexto brasileiro, a posição da disciplina no currículo e como este novo posicionamento pode contribuir, ou não, para rever os discursos que promovem os binarismos opressivos na escola e na sociedade. Estas questões quando tratadas por meio da perspectiva "póscolonial" podem possibilitar ao AP compreender as relações de poder que estiveram e ainda estão presentes em diferentes momentos da história.

Desta forma, o que se propõe é compreender os sentidos que o AP constrói na condição de AP brasileiro de LI. Novamente, não se trata apenas de ser aluno e ser professor, mas da construção de sentidos da LI nesta constituição. Nessa construção de sentidos, o significado pressupostamente definido do que é ser professor e do que é ser aluno de LI passa a ser analisado sob uma perspectiva menos direta, menos óbvia, ou seja, não se está pensando no significado de aluno enquanto sujeito passivo, mas na construção de algo ainda em processo de ressignificação.

Conforme enfatiza Menezes de Souza, ao discutir hibridismo e a representação a partir dos textos teóricos de Bhabha, "o significado, portanto, não é algo que pode ser recuperado através de uma referência direta a uma origem "real" postulada" (2004, p. 116). Nesse sentido, o significado do que é ser aluno e do que é ser professor de inglês e de como o licenciando é afetado por esta língua outra é construído e reconstruído no contato com o outro, estrangeiro ou não, durante a experiência diária com a LI. Como fruto de condições determinadas de produção e do trabalho da interpretação, o significado não é transparente ou dado, mas constituído por "traços" de outros discursos (DERRIDA, 2001) que não comportam um acesso ao original, pois este também é marcado por traços que produzem novos significados e discursos e, nesse processo, o novo dá lugar à 


\section{Revista do SELL \\ v. $4, \mathrm{n}^{\circ} .1$ \\ ISSN: $1983-3873$}

negociação de significados e das representações. Não é mais um mesmo nem um outro, mas um novo que carrega o mesmo e o outro. Não é mais o símbolo, mas o signo. (MENEZES DE SOUZA, 2004).

O licenciando não deve ser visto como um aluno dentro de uma concepção originária do que significa ser um aluno ou a partir da crítica freireana - como alguém que recebe os ensinamentos do mestre, passivo e pronto para aplicar o conteúdo tal qual foi aprendido, tampouco ele deve ser visto como um professor dentro desta mesma perspectiva, mas sim como alguém que pode negociar os significados do que é ser os dois nesta etapa da graduação.

Essa identidade híbrida, no entanto, não é favorecida no curso de Letras. A forma como o curso de Letras está estruturada conduz o AP a uma vivência em direção à binaridade. Ao obstaculizar a experiência de docência ao AP, desde o início do curso, permite-se que ele posicione-se como aluno durante a primeira fase do curso e viva a multiplicidade das identidades apenas na segunda parte do curso quando ocupa tanto a posição de aluno quanto de professor. Este tipo de situação não permite que haja tempo para que o AP compreenda-se como um professor em construção, mas como alguém que precisa estar pronto, completo até o final do curso, o que pode fazer com que ele angustie-se na luta por uma identidade fixa.

É nesse espaço, nessa fronteira da cultura e da língua, de aluno e de professor, que o licenciando pode negociar o Eu e o Outro em "uma passagem intersticial entre identificações fixas [que] abre[m] a possibilidade de um hibridismo cultural que acolhe a diferença sem uma hierarquia suposta ou imposta" (BHABHA, 1998, p.22).

Isto não quer dizer que o hibridismo interrompe o conflito e cria uma situação de homogeneidade, ao contrário, ele

não é um terceiro termo que resolve a tensão entre duas culturas, ou as duas cenas do livro, em um jogo dialético de "reconhecimento". O deslocamento de símbolo a signo cria uma crise para qualquer conceito de autoridade baseado em um sistema de reconhecimento: a especularidade colonial, duplamente inscrita, não produz um espelho onde o eu apreende a si próprio; ela é sempre a tela dividida do eu e de sua duplicação, o híbrido (BHABHA, 1998, p.165, grifos do autor).

No caso desta discussão, reconhecer o AP na perspectiva da identidade híbrida é possibilitar que os conflitos possam ser vividos e trabalhados de uma maneira que eles sejam vistos como parte do processo de tornar-se professor. Nesse processo, todos os momentos vivenciados pelo AP podem conduzi-lo para a compreensão das identidades 


\section{Revista do SELL \\ v. $4, \mathrm{n}^{\circ} .1$ \\ ISSN: $1983-3873$}

que o envolvem e o envolverão mesmo depois do término do curso, pois "a hibridização é precisamente o fato de que quando uma nova situação, uma nova aliança se formula, pode exigir que você traduza, expanda e repense os seus princípios ${ }^{10 " ~(B H A B H A, ~ 1990, ~}$ 216, tradução nossa). Essa hibridação mencionada por Bhabha é utilizada aqui no sentido de que o licenciando, na condição de AP de língua inglesa, deveria tentar negociar estrategicamente, ao longo do curso, o seu lugar por meio do repensar, da revisão dos posicionamentos, os quais precisa constantemente ocupar durante os diferentes momentos da formação. Ao confrontar as identidades de aluno e de professor falante de português brasileiro e de aluno e de professor falante de inglês, o licenciando precisa expandir as concepções de língua, de ensino, de aprendizagem e de cultura que o envolvem, precisa repensá-las e traduzi-las. Esse negociar, na forma como eu o entendo, é justamente o terceiro espaço que

embora irrepresentável, constitui as condições discursivas enunciativas que garantem que o significado e os símbolos da cultura não tenham unidade ou fixidez primordial e que até os mesmos signos possam ser apropriados, traduzidos, re-historizados e lidos de outro modo" (BHABHA, 2010, p.68).

Embora o AP ocupe este terceiro espaço enunciativo no qual os símbolos, no contato com mundo cultural e linguístico do outro, possam ser lidos de formas diferentes, ele ainda tem sido chamado a imitar um falante nativo de inglês e não a posicionar-se como falante culturalmente hibridizado de uma língua estrangeira.

\section{Contribuições finais}

Discutir a condição de AP de língua inglesa significa ser chamado a repensar a forma como a língua, a cultura, a estrutura curricular e, consequentemente, o estágio supervisionado tem sido construído a partir de uma perspectiva binária. Repensar estas questões pode significar um reposicionamento em relação aos velhos conceitos que as envolvem pela desestabilização da ideia de pertencimento a uma língua, a uma cultura ou outra, de um posicionamento ou outro e perceber-se ocupando espaços diferentes numa constante reconstituição de si mesmo e do outro. Essas ocupações distintas não deixam de carregar os "rastros" das experiências vividas nos mais diversos momentos e, que por assim ser, nos fazem estar sempre em num novo lugar, em uma nova posição que não é

\footnotetext{
10 "(...) and hybridity is precisely about the fact that when a new situation, a new alliance formulates itself, it may demand that you should translate your principles, rethink them, extend them". (BHABHA, 1990, p. 216).
} 
nem uma nem outra, mas "algo a mais, que contesta os termos e territórios de ambos" (BHABHA, 1998, p.55).

Discutir a identidade do AP pela perspectiva da identidade híbrida requer uma profunda revisão das concepções de ensino e de aprendizagem praticadas no ensino superior, demanda também uma constante reformulação do próprio fazer docente, da estrutura curricular e institucional enraizados num fazer fixo e bancário.

\section{Referências}

ANDREOTTI, V. Actionable Postcolonial Theory in Education. New York: Palgrave Macmillan, 2011.

BHABHA, H. The Third Space. Interview with Homi Bhabha: depoimento.. London: Identity: Community, Culture, Difference. Entrevista concedida a Jonathan Rutherford, 1990.

O local da cultura. Tradução de Myriam Ávila; Eliana Lourenço de Lima reis; Gláucia Renate Gonçalves. Belo Horizonte: Editora UFMG, 1998.

BHABHA, H.; COMAROFF, J. Speaking of Postcoloniality in the Continuous Present: a Conversation. Relocating Postcolonialism. Ed. David Theo Goldberg and Ato Quayson. Oxford: Blackwell, 2002.

BARCELOS, A. M; BARBARA, F. de Sá; ANDRADE, J. C. Ser professor de Inglês: Crenças, expectativas e dificuldades dos Alunos de Letras. In: ABRAHÃO, Maria Helena Vieira. (Org.) Prática de Ensino de Língua Estrangeira: Experiências e Reflexões. Campinas, SP: Pontes Editores, ArteLíngua, 2004. p. 11-29.

BRASIL. Ministério da Educação. Conselho Nacional de Educação. Parecer CNE/CP nº 028/2001. Nova redação ao Parecer CNE/CP 21/2001, que estabelece a duração e carga horária dos cursos de formação de professores da Educação Básica, em nível superior, curso de licenciatura, de graduação plena.

Ministério da Educação. Conselho Nacional de Educação. Parecer CNE oㅡ 009/2001. Diretrizes Curriculares Nacionais para a Formação de Professores da Educação Básica, em nível superior, curso de licenciatura de graduação plena.

Ministério da Educação. Conselho Nacional de Educação. Parecer CNE/CP № 027/2001. Dá nova redação ao item 3.6, alínea c, do Parecer 9/2001, que dispõe sobre as Diretrizes Curriculares Nacionais para a Formação de Professores da Educação Básica, em nível superior, curso de licenciatura de graduação plena.

Ministério da Educação. Lei de Diretrizes e Bases da Educação Nacional, noㅡ $\overline{9.394, \text { de }} 20$ de dezembro de 1996. 
Ministério da Educação. Resoluções CP/CNE 01. Institui as Diretrizes Curriculares Nacionais para a Formação de Professores da Educação Básica, em nível superior, curso de licenciatura, de graduação plena. Diário Oficial da República Federativa do Brasil, Brasília, DF, 9 de abril de 2002. Seção I, p. 31.

. Ministério da Educação. Resoluções CP/CNE 02. Institui a duração e a carga horária dos cursos de licenciatura, de graduação plena, de formação de professores da Educação Básica em nível superior. Diário Oficial da República Federativa do Brasil, Brasília, DF, 4 de mar. de 2002. Seção I, p. 9.

COSTA, S. Desprovincializando a sociologia: a contribuição pós-colonial. Revista Brasileira de Ciências Sociais, 21(60), 2006, p.117-134.

CURY, J. Estágio nas licenciaturas: 300 horas. In: Anais do I Encontro Nacional de Estágios. Aspectos Éticos e legais. Curitiba: UFPR, 1997. p.38-50.

DANIEL, F. Formação Inicial do professor de língua inglesa: Teoria e prática em questão. São José do Rio Preto, 2000. 317f. Tese (Doutorado em Estudos Linguísticos). Universidade Estadual Paulista Júlio de Mesquita Filho, São José do Rio Preto, 2009.

DERRIDA, J. Posições. Belo Horizonte, Minas Gerais: Autêntica, 2001. Gramatologia. São Paulo: Perspectiva, 2008.

FANON, F. Pele negra, máscaras brancas. Rio de Janeiro: Fator, 1983.

FERNANDES, V. L. D. As crenças e práxis de professores de língua inglesa em formação e o aprendizado autônomo. Porto Alegre, 2005. (Doutorado em Letras) Instituto de Letras, Universidade Federal do Rio Grande do Sul, Porto Alegre, 2005.

FREIRE, P. Pedagogia do Oprimido. 17º ed.Rio de janeiro: Paz e terra. 1987.

GANDHI, L. Postcolonial theory: A critical introduction. Edinburgh University Press, 1998.

GIMENEZ, T. As práticas no Curso de Licenciatura em Letras-Inglês da Universidade Federal de Santa Catarina. In: ABRAHÃO, Maria Helena Vieira (Org.) Prática de Ensino de Língua Estrangeira: Experiências e Reflexões. Campinas, SP: Pontes Editores, ArteLíngua, p. 171-187, 2004.

Desafios contemporâneos na formação de professores de línguas: contribuições da Linguística Aplicada. In: Linguística Aplicada e Contemporaneidade. In: FREIRE, M. M; ABRAHÃO, M. H V; BARCELOS, A. M. F. (Org.) Campinas, SP: Pontes, p. 183201, 2005.

HALL, S. A identidade Cultural na Pós-modernidade. 10ํㅡ. Ed. Rio de Janeiro: DP\&A, 2005

Da diáspora: identidades e mediações culturais. (org) Liv Sovik: Tradução Adeline La Guardia Resende. et.al. 1 ed. atualizada. Belo Horizonte: Editora UFMG, 2011. 
Quem precisa de identidade? In: SILVA, Tomaz Tadeu; HALL Stuart; WOODWARD, Kathryn (org.). Identidade e diferença: a perspectiva dos estudos culturais. 9.ed. Petrópolis: Vozes, 2009. p. 103-133.

HUDDART, D. Homi Bhabha. Routledge. London e New York. 2006.

JORDÃO, C. M. A posição de professor de inglês no Brasil: hibridismo, identidade e agência. R. Letras \& Letras. Uberlândia-MG v.26 n.2 p. 427-442 jul-dez. 2010.

KIERNAN, P. Narrative Identity in English Language teaching. Exploring Teacher interviews in Japanese and English. United Kinddom: Palgrave Macmilan, 2010.

KINCHELOE, J. L. A formação do professor como compromisso político: mapeando o Pós-Moderno. Porto Alegre: Artes Médicas, 1993.

KUMARAVADIVELU, B. The postmethod condition: (E)merging strategies for second/foreign language teaching. TESOL Quarterly, vol 28, N1, 1994.

LOPES, O; VEIGA, I. P. at. al. Repensando a diática. 4.ed. Campinas, SP: Papirus, 1990.

MACHADO, I. J. Reflexões sobre o pós-colonialismo. Teoria \& pesquisa. São Carlos, v. 44/45, n. jan/jul, 2004.

MENEZES DE SOUZA, L. M. T. Hibridismo e Tradução Cultural em Bhabha. In: Benjamin Abdala Junior. (Org.). Margens da Cultura: mestiçagens, hibridismo e outras misturas. São Paulo: Boitempo Editorial, 2004, v, p. 113-133.

OLIVEIRA, L. E. A imprensa e o ensino de línguas no século XIX: o caso da província de Sergipe (1843-1888). Revista da FAPESE de Pesquisa e Extensão, v. 2, p. 23-36, 2006.

PIMENTA, S. G; LIMA, M. S. L. Estágio e docência. São Paulo: Cortez, 2004.

RICHARDS, J. C; RODGERS, T.S. Approaches and Methods in Language Teaching. 2. ed. Cambridge: Cambridge University Press, 2001.

RIGOLON, P. S. T. O trabalho monográfico: um instrumento mediador da reflexão crítica na formação inicial do professor de língua inglesa. São Paulo, 2006, 115p. Tese (Doutorado em Linguística Aplicada e Estudos da Linguagem). Pontifícia Universidade Católica de São Paulo, São Paulo, 2006.

RODRIGUES, B. G. Formação de professores de língua inglesa em um curso de Letras com habilitação única em inglês. São Paulo. 2007.Tese (Doutorado em Linguística Aplicada e Estudos da Linguagem). Pontifícia Universidade Católica de São Paulo, 2007.

RUTHERFORD, J. The Third Space. Interview with Homi Bhabha. In: Ders. (Hg): Identity: Community, Culture, Difference. London: Lawrence and Wishart, 1990. 
SAID, E. Orientalismo. O oriente como invenção do ocidente. São Paulo: Companhia das Letras, 2007.

SILVA, T. T da. (Org.) Identidade e diferença. A perspectiva dos Estudos Culturais. 9ำ ed. Petrópolis: Vozes, 2009.

Documentos de identidade: uma introdução às teorias do currículo. $3^{\circ}$ ed., Belo Horizonte: Autêntica, 2010.

TREJO-GUZMAN, N. P. The teacher self construction of language teachers. Submitted by Nelly Paulina Trejo-Guzmán. University of Exeter. Thesis for degree of doctor of education in TESOL. 2010.

VAILLANT, D. Formação de Formadores: estado da prática. Rio de Janeiro: PREAL (Programa de Promoção da Reforma Educativa na América Latina e Caribe), 2003.

XAVIER, R. P. As práticas no Curso de Licenciatura em Letras-Inglês da Universidade Federal de Santa Catarina. In: ABRAHÃO, Maria Helena Vieira (Org.) Prática de Ensino de Língua Estrangeira: Experiências e Reflexões. Campinas, SP: Pontes Editores, Arte Língua, 2004. p.153-169. 